Research Article

\title{
Experimental Study on the Effects of Stress-Induced Damage on the Microstructure and Mechanical Properties of Soft Rock
}

\author{
Hao Wang $\mathbb{D}^{1,2}$ Yong-Yan Wang, ${ }^{1}$ Zhuo-Qun Yu ${ }^{\mathbb{D}},{ }^{1}$ and Jian-Guang Li $^{1}$ \\ ${ }^{1}$ Department of Electrical and Mechanical Engineering, Qingdao University of Science and Technology, Qingdao 266000, \\ Shandong, China \\ ${ }^{2}$ Wuhan Institute of Rock and Soil Mechanics, Chinese Academy of Sciences, Wuhan 430000, Hubei, China
}

Correspondence should be addressed to Hao Wang; qust_wh2020@126.com

Received 28 November 2020; Revised 13 January 2021; Accepted 18 January 2021; Published 31 January 2021

Academic Editor: Guoyang Fu

Copyright (c) 2021 Hao Wang et al. This is an open access article distributed under the Creative Commons Attribution License, which permits unrestricted use, distribution, and reproduction in any medium, provided the original work is properly cited.

After rocks are damaged under stress loading, the changes of their microstructural and mechanical properties are major factors that affect construction safety in geotechnical engineering projects. Studying the microstructures and mechanical behaviors of stress-damaged rocks can help better guide construction and reduce construction risks for geotechnical engineering projects. In this study, a sandstone was first artificially predamaged and then subsequently subjected to scanning electron microscopy (SEM) analysis, computed tomography (CT) scanning, and uniaxial compression testing. Afterwards, the rock microstructures were three-dimensionally (3D) reconstructed, and the pores were classified and characterized based on their diameters. Moreover, the microstructural and mechanical parameters of the rock were subjected to significance analysis. The results showed that as the stress-induced damage $\left(\sigma_{i}\right)$ increased, the uniaxial compressive strength $\left(\sigma_{c}\right)$ of the soft rock decreased by $13.7-31.8 \%$; as $\sigma_{i}$ increased from 11.2 to $19.6 \mathrm{MPa}$, the elastic modulus $(E)$ of the soft rock increased by up to $28.8 \%$; and as $\sigma_{i}$ increased beyond $19.6 \mathrm{MPa}$, there was a significant $(22.3 \%)$ decrease in $E$. Stress-induced damage significantly affected the spatial distribution of the pores' structure of the soft rock. Changes in the spatial structure of the pores led to the formation of cracks. The microstructural parameters of the stress-damaged soft rock were correlated with its mechanical parameters.

\section{Introduction}

At the microscopic level, rocks are discontinuous and inhomogeneous and contain natural defects, such as pores, cracks, and joints [1]. After rocks sustain damage (e.g., stress-induced damage, chemical erosion, and fatigue-induced damage) from external causes, their original defects can develop and subsequently change their mechanical properties $[2,3]$. Stressinduced damage is the principal type of damage that occurs during geotechnical engineering construction (e.g., tunneling and mining for underground resources). The mechanical properties of stress-damaged rocks affect construction safety in geotechnical engineering projects. Meanwhile soft rock is a type of porous material of which the internal microstructure dictates its mechanical properties. Therefore, it is critically important to accurately characterize and evaluate damageinduced microstructural changes in rocks.

With advancements in detection technology, scanning electron microscopy (SEM), acoustic emission (AE) testing $[4,5]$, and computed tomography (CT) scanning $[6,7]$ have been gradually applied to microstructural characterizations and evaluations of rocks. Chen et al. [8] examined the AE characteristics of sandstone with a uniaxial compression failure test and found that AEs could be used to characterize various stages of the uniaxial compression failure process of the sandstone. Shuang et al. [9] characterized the internal microstructural damage of rock at various loading rates using the $\mathrm{AE}$ technique and found that this technique could characterize the specific locations where internal damage occurred. To further explain the microscopic mechanisms by 
which rocks sustain damage, some researchers have employed SEM to characterize rocks at the microscopic level. Qin et al. [10] investigated the effects of water invasionwater loss cycles on the microstructure of rock by SEM and found that microstructural changes in the rock under water invasion-water loss cycles exhibited four stages. Yang et al. [11] studied microstructural changes of a rock under wetting-drying cycles and determined the changes in pore parameters (e.g., porosity, pore size, and pore shape) through SEM by increasing the number of wetting-drying cycles. Tao et al. [12] examined the evolution of cracks in elliptical-hole-bored granitic rocks under dynamic loading and used SEM to characterize the responses of the constituent minerals at different stages of the failure process. SEM can be used to determine the microstructural forms and morphologies of damaged rocks. Compared to the AE technique, SEM is capable of characterizing damage-induced microstructural changes in rocks in a more accurate and comprehensive fashion. However, both the SEM and AE methods are only able to qualitatively characterize rock microstructures. Inspired by medical CT scanning, some researchers have applied CT to obtain quantitative characterizations of rock microstructures. As evidenced by its working principle $[13,14]$, CT scanning is superior to AE and SEM techniques for characterizing microstructural damage in rocks. Some researchers have characterized and evaluated damaged rocks by the use of CT scanning [15-18]. All of these research results have demonstrated the tremendous advantages of CT scanning for characterizing rock microstructures.

Currently, CT scanning is the most advanced technical method for characterizing and evaluating rock microstructure. Two-dimensional (2D) CT scan slices can accurately characterize rock microstructures. However, 2D CT scan slices are unable to characterize the spatial distributions of rock microstructures and their changes. So three-dimensional (3D) spatial characterization of rock microstructures has become a research hotspot and has been pursued by numerous researchers. Nevertheless, the use of $\mathrm{CT}$ and $3 \mathrm{D}$ reconstruction techniques to examine the effects of stress-induced damage on rock microstructures has yet to be studied adequately in depth. In this study, SEM, CT, and 3D reconstructions were combined to qualitatively and quantitatively characterize microstructural changes in rock after sustaining damage under stress loading. In addition, the mechanism of microstructural changes was elucidated. Moreover, the mechanical and microstructural parameters of the rock were analyzed using statistical analysis methods.

\section{Materials and Methods}

Figure 1 shows the experimental procedures and equipment. There were four steps in the experiments. Firstly, rocks were machined into standard samples, which were maintained for 28 days. Secondly, a Hitachi SU8000 SEM system was used to observe the slices extracted from the samples. Then, a nanoVoxel 3000 high-resolution micro-CT scanner was employed to scan the samples. Finally, TWA-200 electronic material mechanical testing machine was used to perform uniaxial compression tests on the samples which were scanned by nanoVoxel 3000 scanner.

2.1. Sample Preparation. A kind of yellow fine-grained sandstone, which was collected from the Yanzhou coal mine in Jining, Shandong, China, was investigated in this study. According to international rock mechanics standards $[19,20]$ and GB/T 50123-1999, these rocks were machined into standard samples as shown in Figure 1(a). Each sample was $100 \pm 2 \mathrm{~mm}$ in height and $50 \pm 1 \mathrm{~mm}$ in diameter and had a mass of $385 \pm 5 \mathrm{~g}$. The end-surface flatness tolerance was set to $\pm 0.05 \mathrm{~mm}$. The uniaxial compressive strength $\left(\sigma_{c}\right)$ and elastic modulus $(E)$ of the samples were measured to be $28 \pm 0.5 \mathrm{MPa}$ and $4.5 \pm 0.3 \mathrm{GPa}$, respectively. According to the study of Bieniawski and Bernede [20], when the load $\left(\sigma_{i}\right)$ is $40-80 \%$ of its $\sigma_{c}$, the internal pores and cracks develop in an unstable fashion, which can damage the rock. On this basis, in this study, the samples were artificially damaged. Specifically, $\sigma_{i}$ that were $40 \%, 50 \%, 60 \%, 70 \%$, and $80 \%$ of $\sigma_{c}$ were applied separately to five samples. Thus, samples that were damaged to various extents were obtained. These samples are denoted as B-S-2, C-S-1, D-S-3, E-S-3, and F-S-2, respectively.

2.2. SEM Observations. The aim of this section was to determine the minimum diameter of pores in the samples by SEM observations and therefore provide a reliable parameter for selecting a suitable resolution for CT scanning. A Hitachi SU8000 SEM system which was shown in Figure 1(e) was used. Three cross sections of a rock sample that had not been artificially damaged were selected from top to bottom at height intervals of $25 \mathrm{~mm}$ for observations. Three rectangular slices with identical dimensions were then selected from each of the three cross-sectional surfaces. Figure 1(c) shows the locations of the selected slices. These slices were subsequently observed at two primary magnifications $(1000 \mathrm{x}$ and 2000x) and one complementary magnification (5000x). Figure 2 shows the SEM images obtained. Based on the SEM images, the minimum diameter of the internal pores of the sample was determined to be $18-25 \mu \mathrm{m}$.

2.3. CT Scanning. nanoVoxel 3000 high-resolution microCT scanner (Tianjin San Ying Precision Instrument Co., Ltd., Tianjin, Hebei, China), as shown in Figure 1(g), was used to scan the samples. This scanner provided a true spatial resolution of $500 \mathrm{~nm}$ and minimum voxel size of $70 \mathrm{~nm}$ and thus met the accuracy required for tests. The minimum pore diameter $(25 \mu \mathrm{m})$, as determined by SEM observations, was taken as the minimum resolution of the CT scans. In the tests, 1440-frame helical CT scanning was performed at a voltage of $180 \mathrm{kV}$ and current of $40 \mathrm{~mA}$. A total of 4,000 2D CT slices with dimensions of 1,800 pixels $\times 1,800$ pixels were obtained for each sample. The rock substrate, cement components, and pores and cracks are shown as white, gray, and black areas in Figure 3, respectively. 


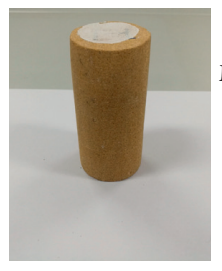

Rock sample

(a)

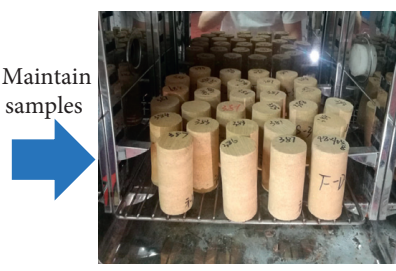

Pictures of samples after maintain

(b)

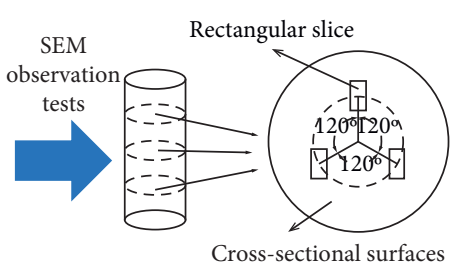

Schematic diagram of the locations of the selected slices

(c)

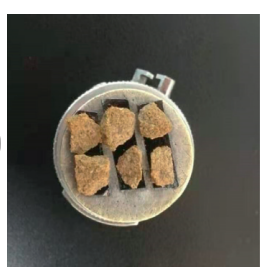

Sample slices

(d)

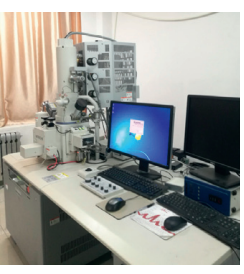

Hitachi SU8000 SEM system

(e)

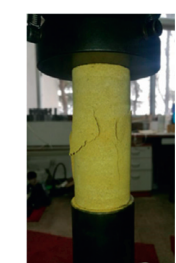

Failed sample unde uniaxial compression

(i)

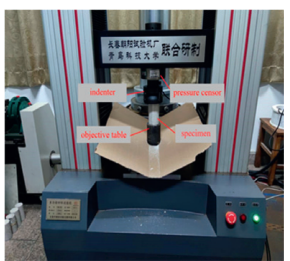

TAW-200 electronic material mechanical testing

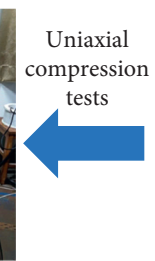

NanoVoxel 3000 3D CT scanner

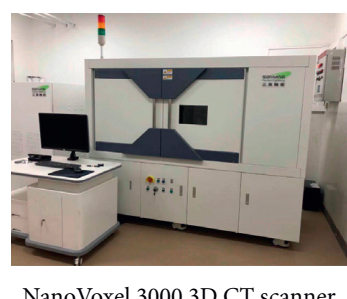

(g)

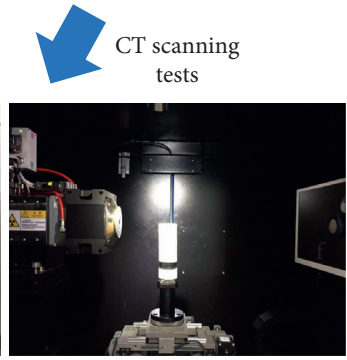

The internal workspace of NanoVoxel 3000 3D CT scanner

(f)

FIGURE 1: Experimental procedures and equipment. (a) Rock sample. (b) Pictures of samples after the maintenance period. (c) Schematic diagram of locations of the selected slices. (d) Sample slices. (e). Hitachi SU8000 SEM system. (f) Internal workspace of the nanoVoxel 3000 CT scanner. (g) nanoVoxel 3000 CT scanner. (h) Photograph of the TAW-200 electronic material mechanical testing machine. (i) Photograph of a sample that failed under uniaxial compression.

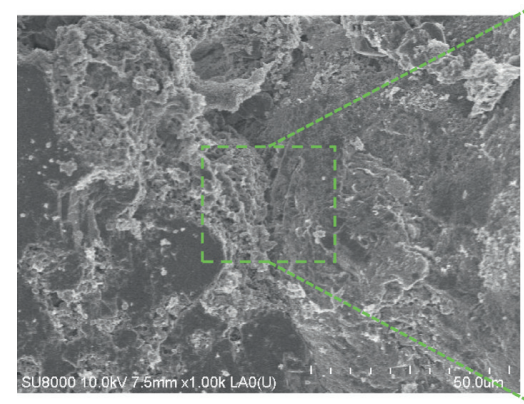

(a)

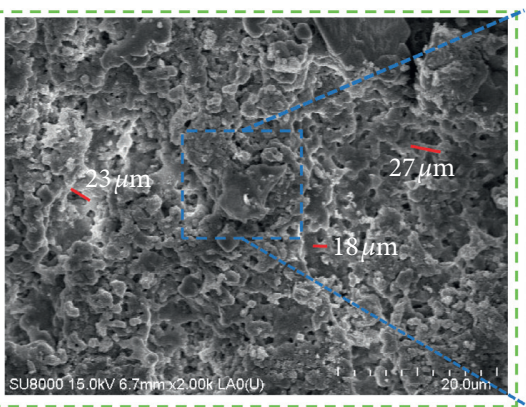

(b)

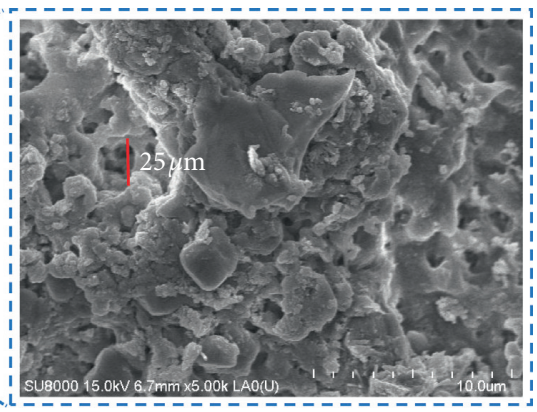

(c)

Figure 2: SEM images at various magnifications. (a) SEM image at 1000x. (b) SEM image at 2000x. (c) SEM image at 5000x.

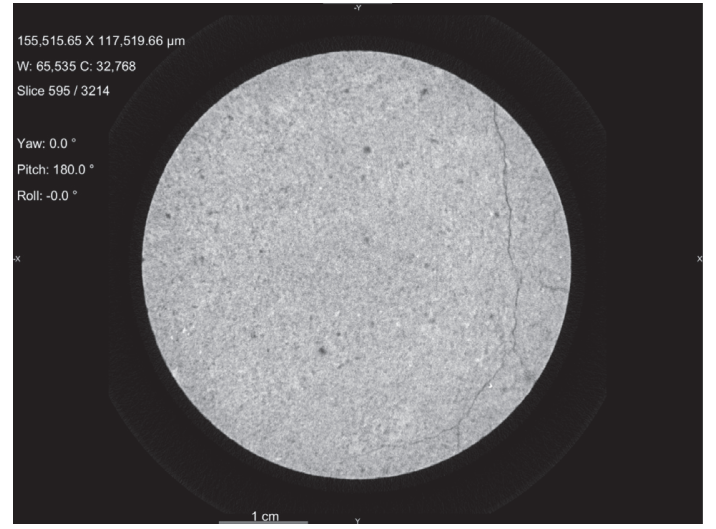

Figure 3: CT slice of a sample.
2.4. Uniaxial Compression Tests. The stress-damaged softrock samples were subjected to uniaxial compression failure testing using a TAW-200 electronic material mechanical testing machine. First, each sample was placed on the test platform of the testing machine, while the center of the sample, center of the base, and center of the indenter were located on the same axis. Then, a computer was used to control the downward movement of the testing machine indenter until its lower end contacted the upper surface of the sample. In addition, a certain prestress $(150 \mathrm{~N})$ was applied to prevent slipping of the indenter, sample, and test platform during the test. Finally, the load control mode was used during the test. According to the test standards [19, 20], each sample was loaded at a rate of $0.1 \mathrm{MPa} / \mathrm{s}$ up to $60 \mathrm{MPa}$ or until failure. During testing, the computer was used to record the test data. 


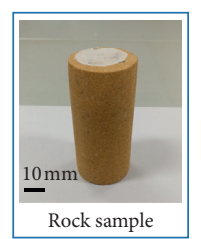

(a)

(h)

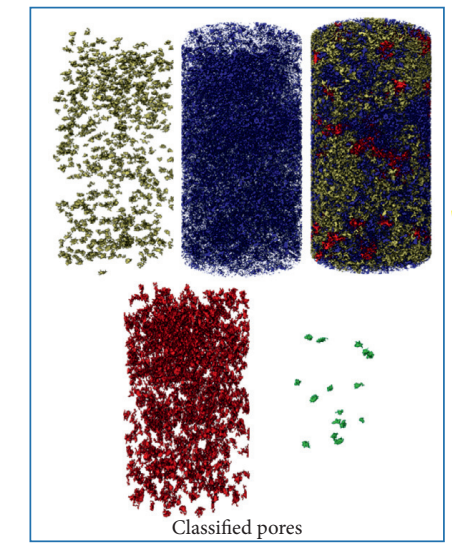

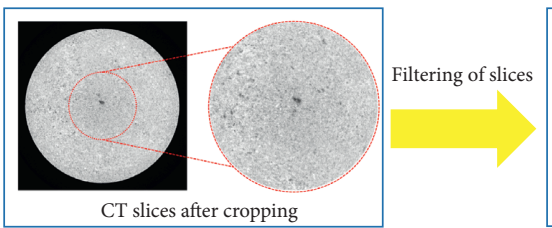

(b)

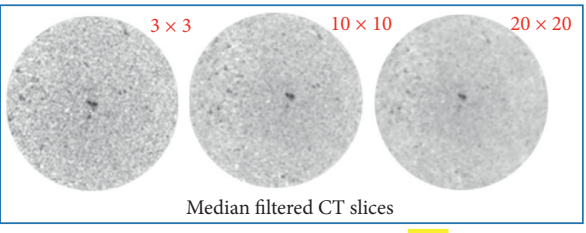

(c)
Binarizing and
filtering of slices

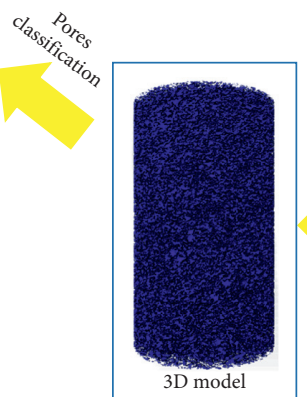

(g)

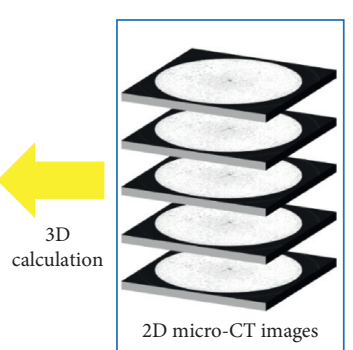

(f)

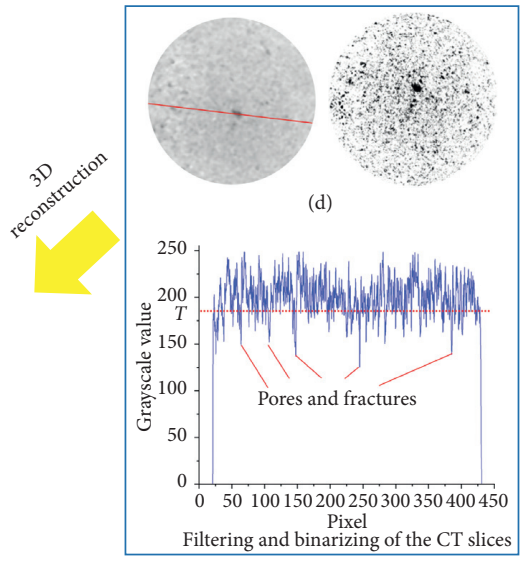

(e)

Figure 4: (a) Rock sample. (b) CT slices after cropping. (c) Median-filtered CT slices. (d) Binarized images of CT slices. (e) Variations in grayscale values along a scan line. (f) $2 \mathrm{D}$ micro-CT images. (g) $3 \mathrm{D}$ model. (h) Pore classification and characterization.

2.5. 3D Reconstruction. Damage-induced microstructural changes in a rock can be qualitatively characterized by $3 \mathrm{D}$ reconstruction. Microstructural parameters extracted from 3D reconstructions can quantitatively characterize microstructural changes in rocks. In this study, 3D reconstruction was achieved in four steps. First, an image from each obtained CT slice was cropped. Second, the cropped images were subjected to median filtering, threshold segmentation, and binarization. Third, the processed CT slices were imported in sequence into Avizo software (version 3.0) for 3D spatial modeling. Finally, the obtained 3D pore models were classified and characterized. Figure 4 shows the 3D reconstruction procedures for the rock.

2.6. Image Processing of CT Slices. In step 1 of the image processing, the CT slices were cropped. When preparing the samples, the pores at the edges of each sample were damaged during the cutting or polishing process, which could affect the observations and analyses of the true pore conditions [21]. An image of 459 pixels $\times 459$ pixels was cropped from each CT slice, as shown in Figure 4(b). However, 4,000 CT slices greatly exceed the available computational capacity for $3 \mathrm{D}$ reconstructions. Thus, 1,000 consecutive CT slices were used for $3 \mathrm{D}$ reconstructions. In step 2, images that were cropped from the CT slices were subjected to filtering and threshold segmentation. A median filter was used in this study to eliminate noise points in the CT slices. Figure 4(c) shows images processed with a median filter using $3 \times 3$, $10 \times 10$, and $20 \times 20$ neighborhood windows. The principle is that the grayscale values of adjacent pixels are weighted and averaged to eliminate noise points. Subsequently, a scan line passing through both the pores and substrate in each median-filtered image was selected, as shown in Figure 4(d) [21]. Figure 4(e) shows the variations in grayscale values along the scan line. The grayscale values above and below the scan line are those of the substrate and pores, respectively. This line was used to determine the segmentation threshold $T(T=177)$. Finally, the grayscale values of the image were converted to 0 or 1 by using equation (1) to convert to black/ white contrast images that reflect microscale characteristics, as shown in Figure 4(d).

$$
f^{\prime}(x, y)= \begin{cases}1, & f(x, y) \geq T \\ 0, & f(x, y) \leq T\end{cases}
$$

where $f(x, y)$ and $f^{\prime}(x \cdot y)$ are the initial and postbinarization grayscale values of pixel $(x, y)$, respectively.

2.7. Classified Characterization of Microstructure. The processed CT slices were imported in sequence into Avizo software (version 3.0). The pore structure of each sample was extracted and rendered to produce a $3 \mathrm{D}$ graph, as shown in Figure 5. All pores and fractures were reconstructed and rendered in the same colors as in the 3D reconstruction process. However, in this way, the effects of stress-induced damage on the microstructure of sample could not be easily represented. The SEM observations indicated that as $\sigma_{i}$ increased, significant changes in the pore diameters of the sandstone occurred. Thus, the pores were classified and characterized based on their diameters. Yu used a pore classification that is applied in oil and gas reservoir geology area as a reference $[22,23]$, and the pores were classified into four types based on their diameters, namely, types I 


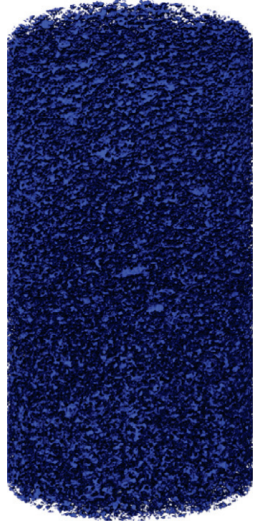

(a)

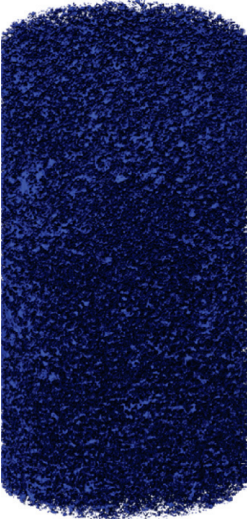

(b)

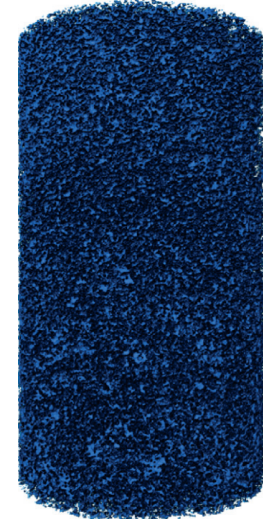

(c)

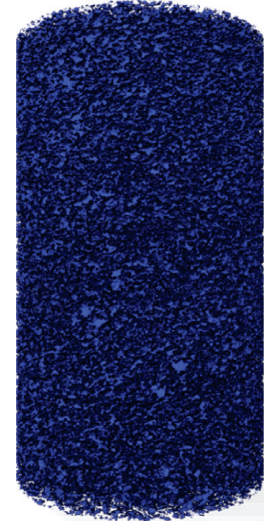

(d)

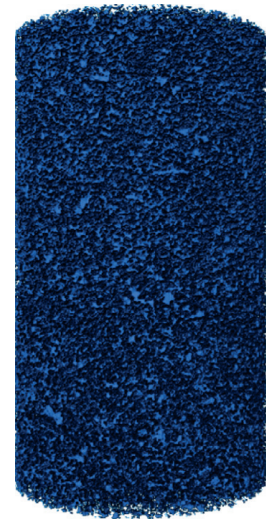

(e)

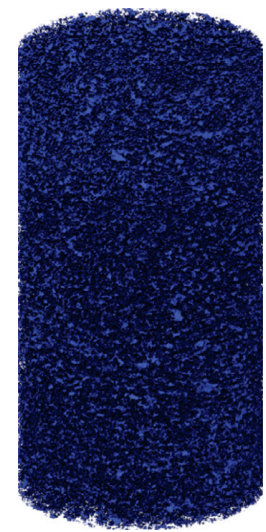

(f)

FIGURE 5: Rendering of all pore structures in the samples.
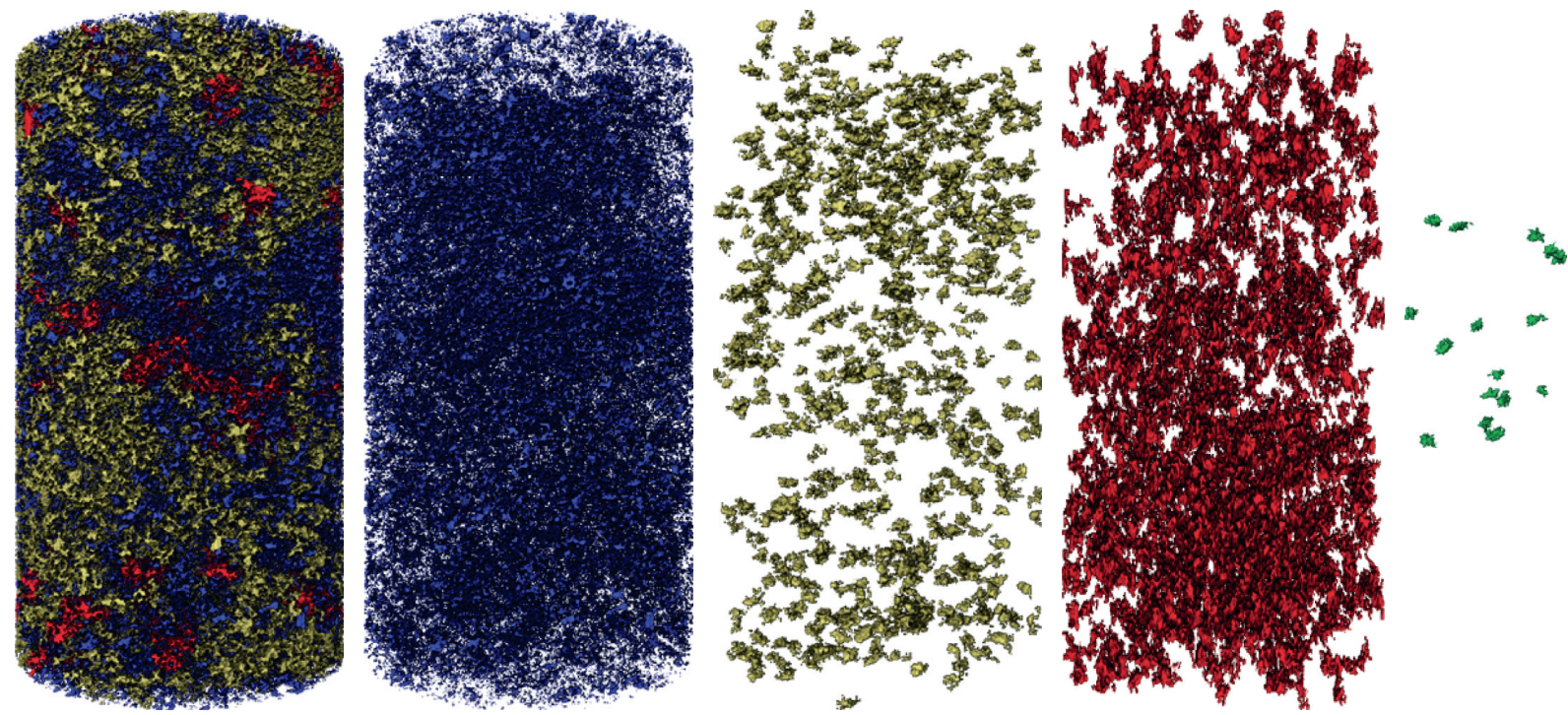

Figure 6: Spatial distribution of the pore structure of sample A-S-1.

(25-75 $\mu \mathrm{m})$, II $(75-130 \mu \mathrm{m})$, III $(130-250 \mu \mathrm{m})$, and IV $(>250 \mu \mathrm{m})$. Figures $6-11$ show the pore classifications and characterization graphs for the samples (types I, II, III, and IV pores are shown in blue, yellow, red, and green, respectively).

\section{Results and Analysis}

As shown in Figures 6-11, stress-induced damage significantly affected the spatial distributions of the pores. When $\sigma_{i}=0$, all pore types were distributed uniformly in the sample, most pores had small diameters $(25-130 \mu \mathrm{m})$, and the pores were poorly interlinked. In terms of the pore numbers $(N)$, type I pores made up the largest proportion and were followed by type II, III, and IV pores. As $\sigma_{i}$ increased, both the connectivity and $N$ values for type I and II pores increased, and both the connectivity and $N$ values for type III and IV pores decreased. The patterns for type III and
IV pores were opposite those of type I and II pores. The connectivity and $N$ values for type I and II pores peaked when $\sigma_{i}=19.6 \mathrm{MPa}$. As $\sigma_{i}$ increased beyond 19.6 MPa, cracks formed in the samples, but the distribution of type I pores was not notably related to that of the cracks and was similar to that of the type I pores in the undamaged sample. Moreover, under this condition, type II, III, and IV pores were concentrated around the cracks.

Six parameters, namely, $N$, porosity $(\varphi)$, and the proportions of type I, II, III, and IV pores $\left(P_{\mathrm{I}}, P_{\mathrm{II}}, P_{\mathrm{III}}\right.$, and $P_{\mathrm{IV}}$, respectively), were calculated for the rock samples using Avizo software (version 3.0). As shown in Figure 12, $N$ decreased as $\sigma_{i}$ increased. The smallest $N$ occurred for a $\sigma_{i}$ value of $22.4 \mathrm{MPa}$. As $\sigma_{i}$ increased, $\varphi$ first decreased and then increased, with a minimum value of $5.7 \%$ and maximum value of $14.9 \%$. The statistical results showed that as $\sigma_{i}$ increased, $P_{\mathrm{I}}$ and $P_{\mathrm{II}}$ first increased and then decreased, with maximum values of $81.3 \%$ and $16.35 \%$ and minimum values 

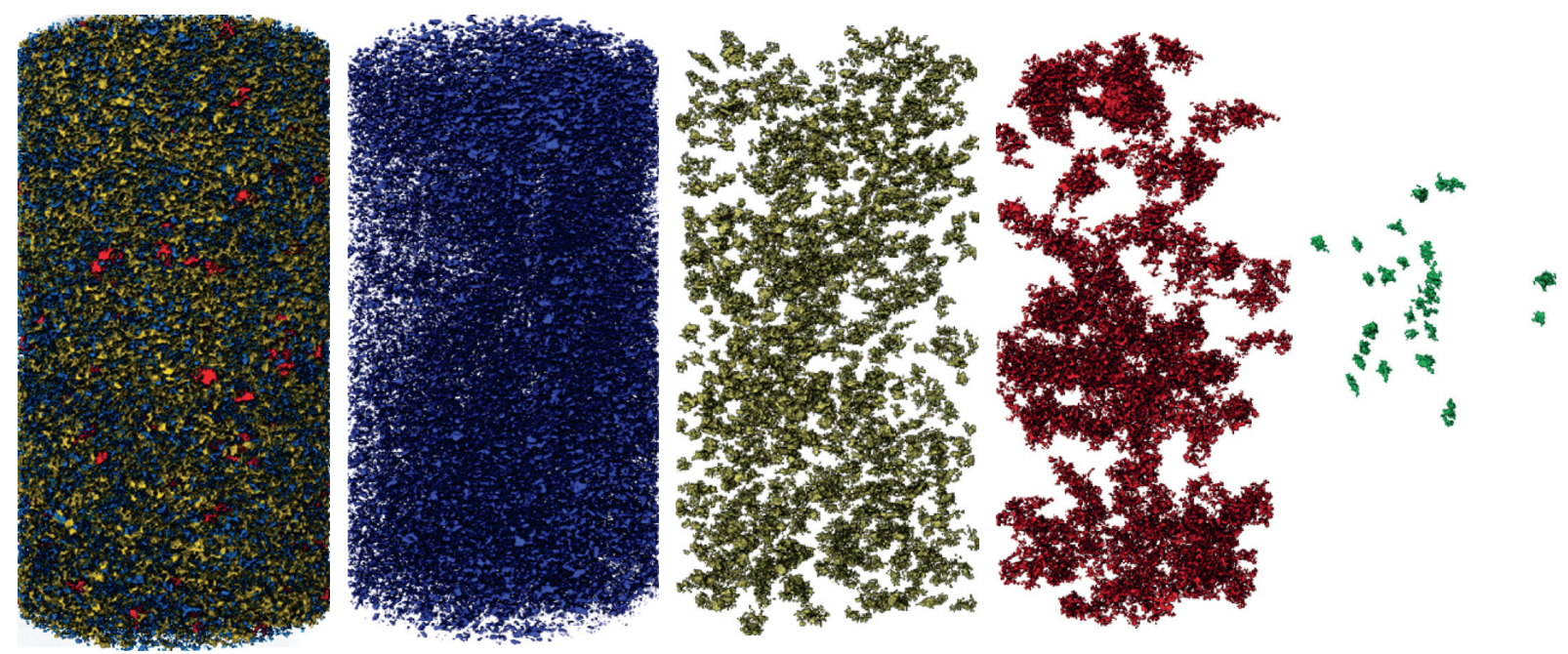

Figure 7: Spatial distribution of the pore structure of sample B-S-2.
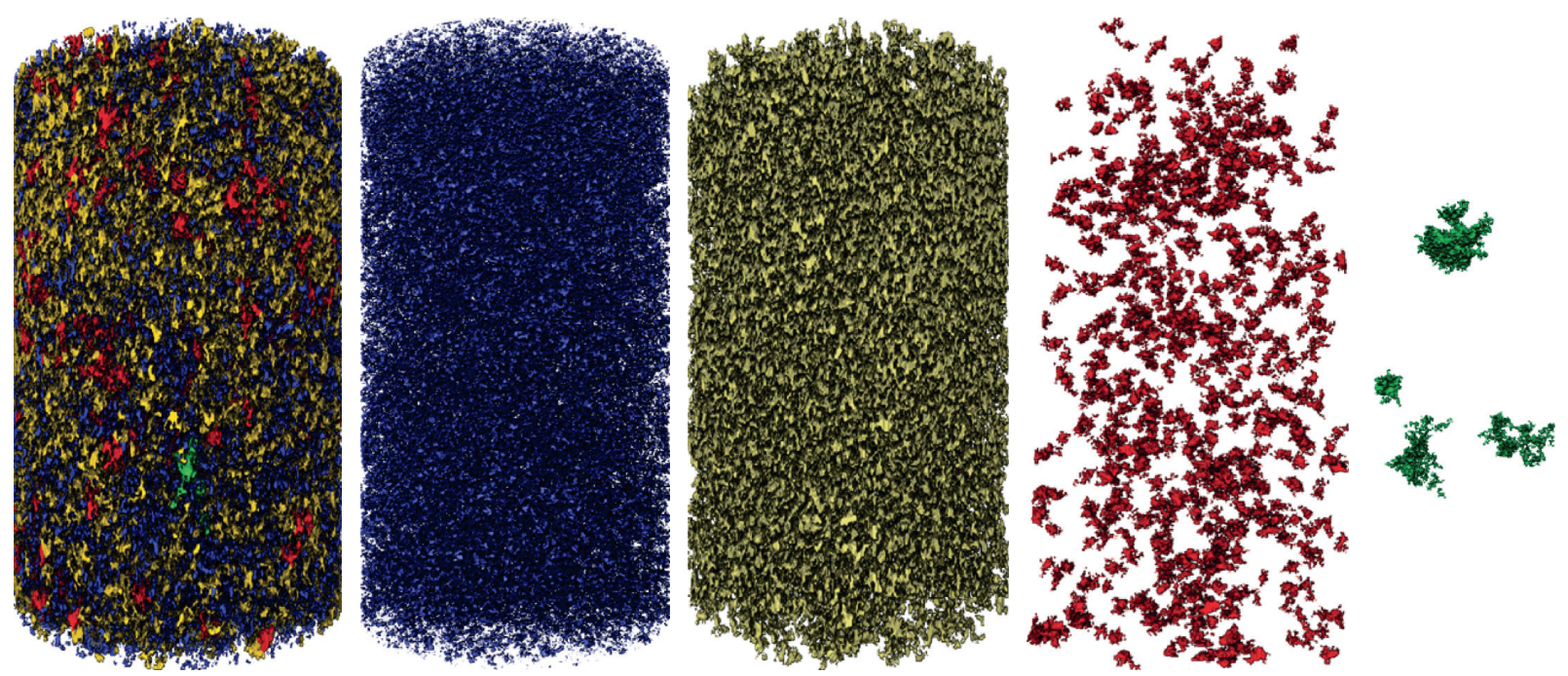

Figure 8: Spatial distribution of the pore structure of sample C-S-1.
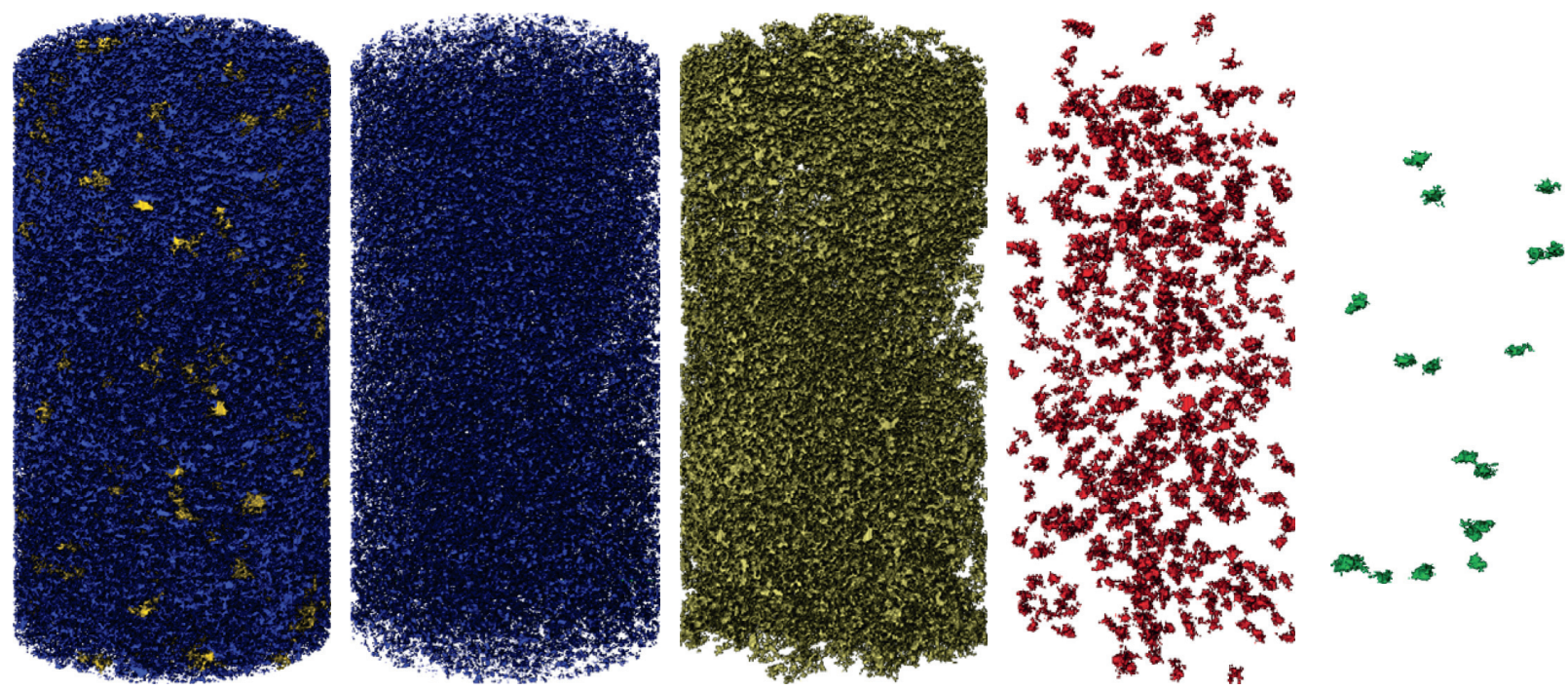

FIGURE 9: Spatial distribution of the pore structure of sample D-S-3. 

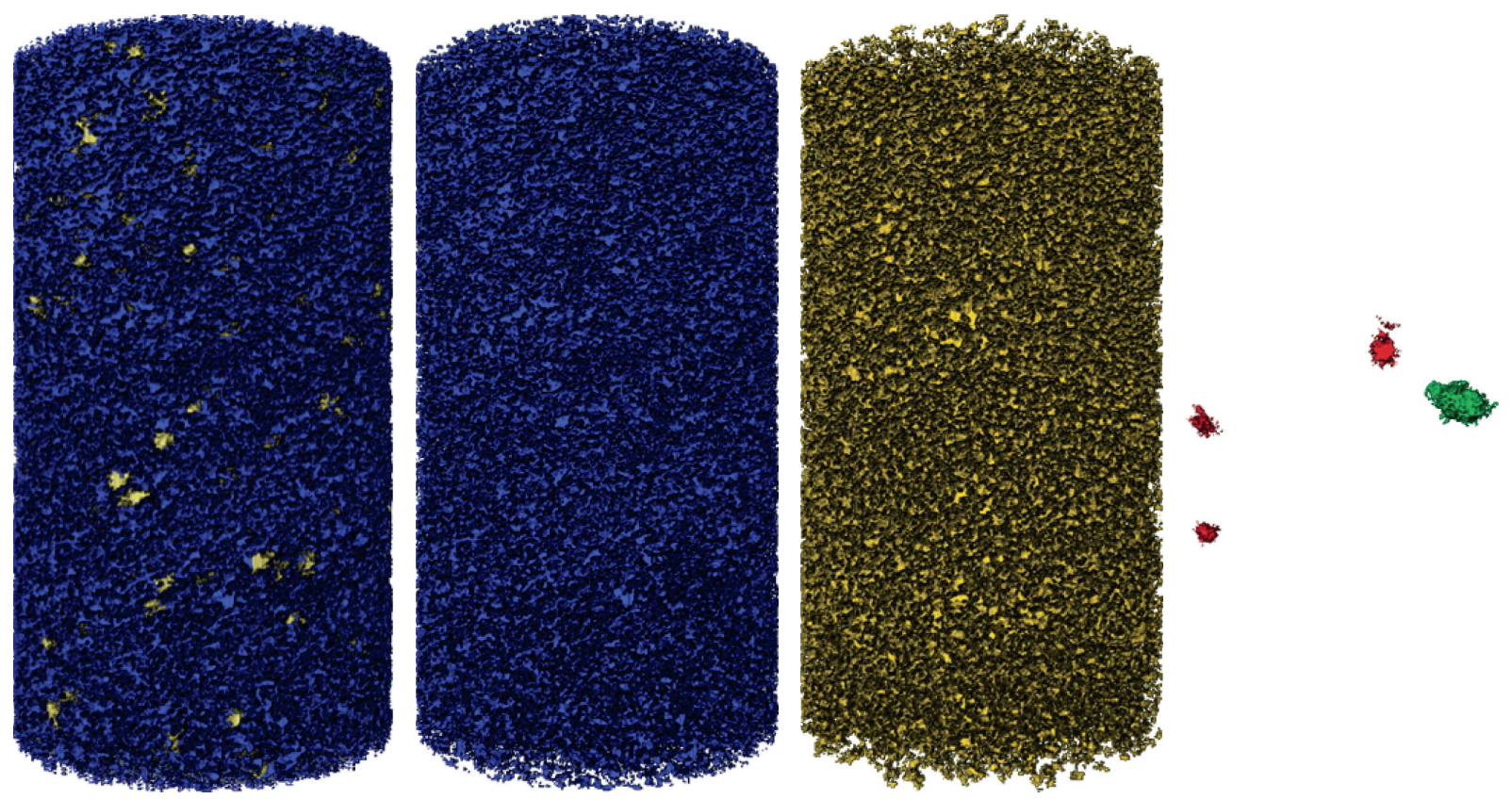

FIgURE 10: Spatial distribution of the pore structure of sample E-S-3.
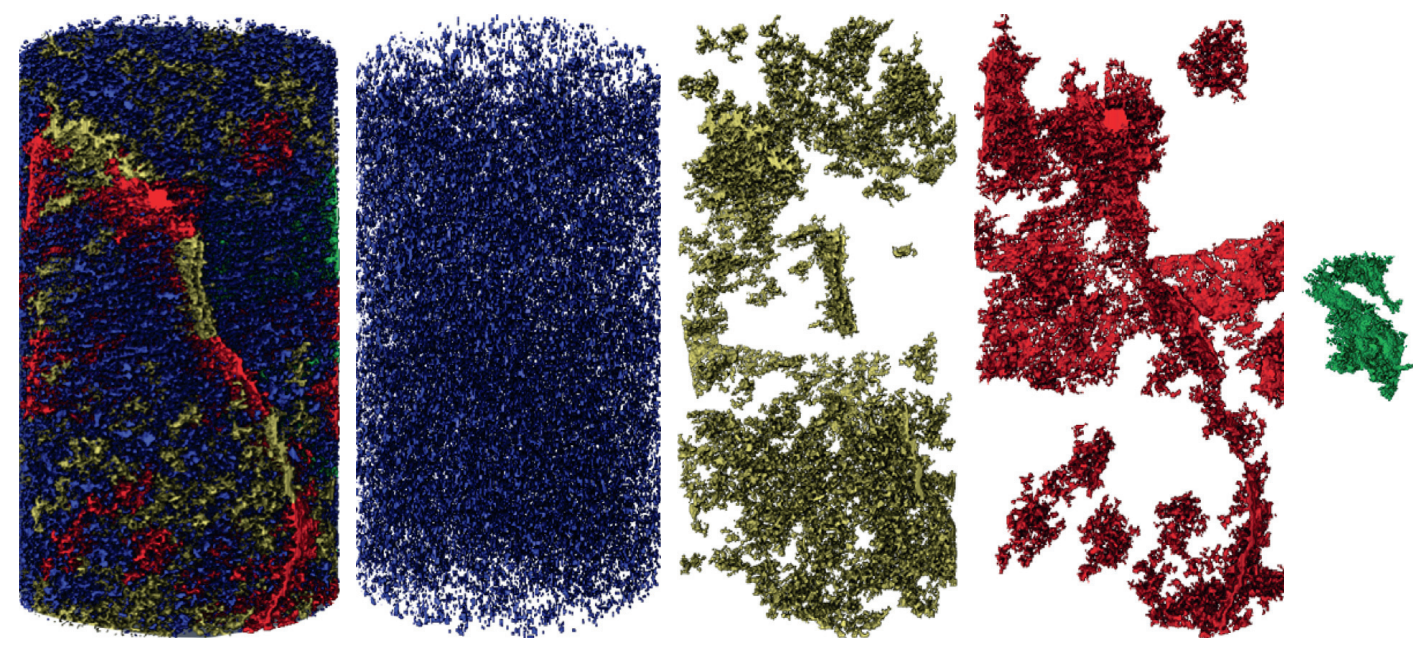

FIGURE 11: Spatial distribution of the pore structure of sample F-S-2.

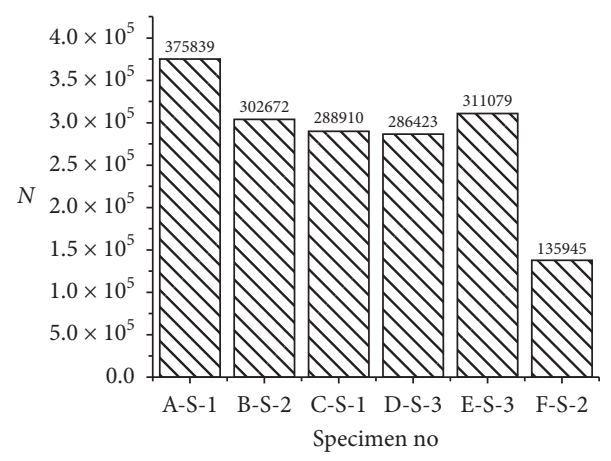

(a)

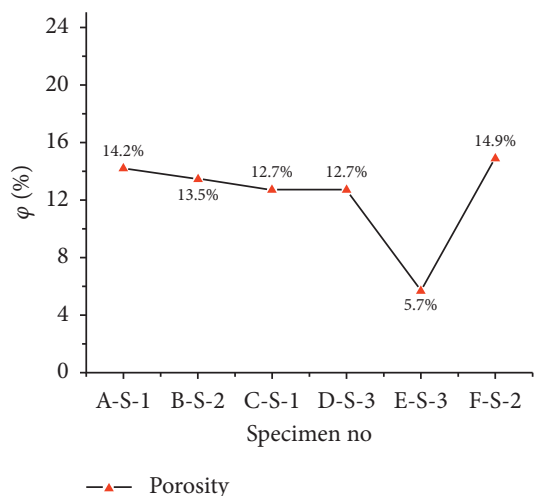

(b)

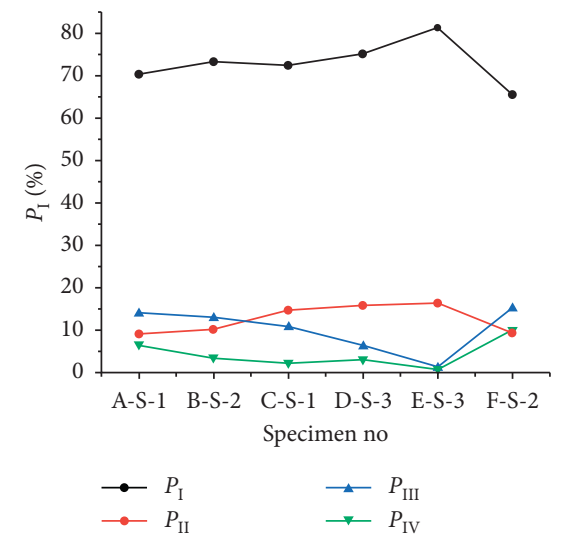

(c)

FIGURE 12: Statistical diagrams of sample microstructural parameters. (a) Number of pores in the samples. (b) Porosities of the samples. (c) Line graphs of $P_{\mathrm{I}}, P_{\mathrm{II}}, P_{\mathrm{III}}$, and $P_{\mathrm{IV}}$. 


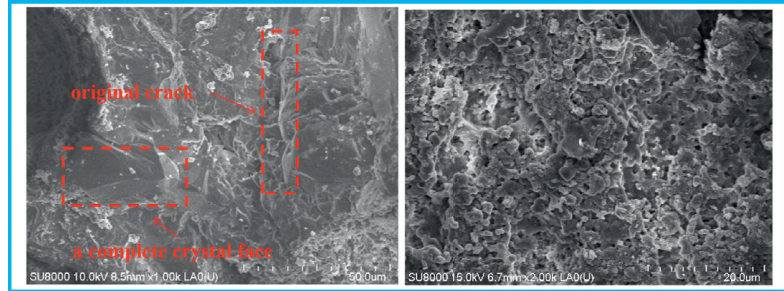

(a)

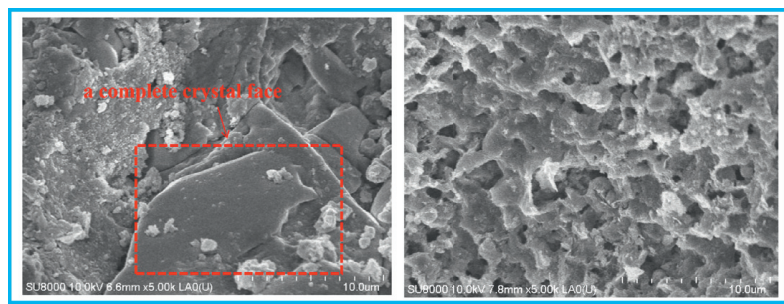

(c)

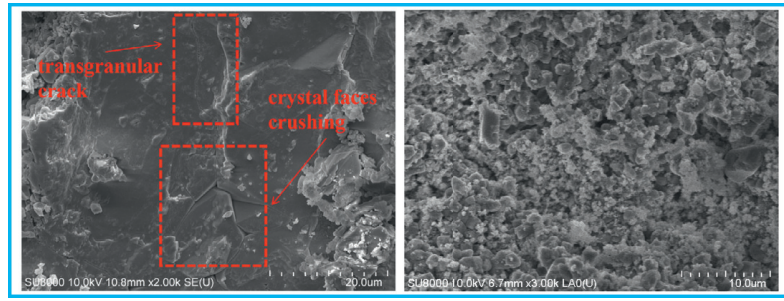

(e)

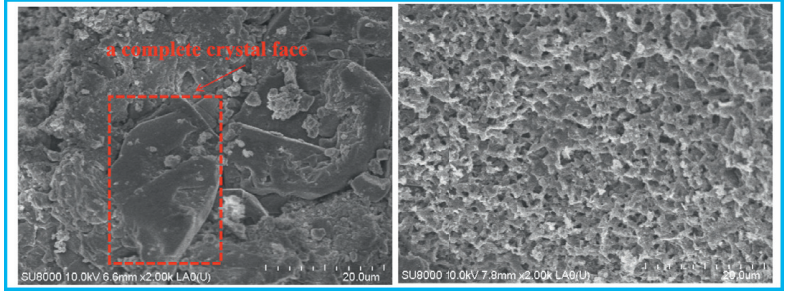

(b)

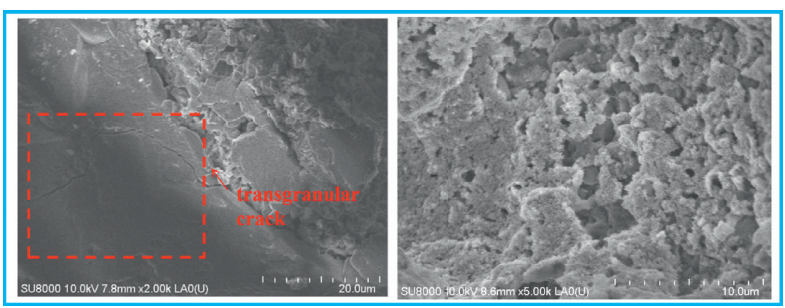

(d)

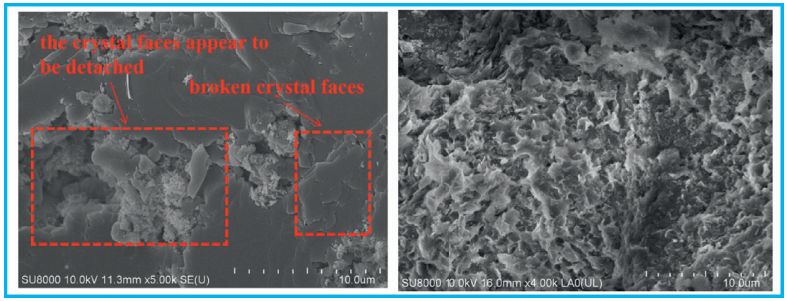

(f)

Figure 13: SEM images of rock fractures and pores in samples A-S-1 (a), B-S-2 (b), C-S-1 (c), D-S-3 (d), E-S-3 (e), and F-S-2 (f).

of $65.5 \%$ and $9.4 \%$, respectively. Notably, as $\sigma_{i}$ increased, $P_{\text {III }}$ and $P_{\mathrm{IV}}$ first decreased and then increased. This pattern for $P_{\mathrm{III}}$ and $P_{\mathrm{IV}}$ was opposite that of $P_{\mathrm{I}}$ and $P_{\mathrm{II}}$.

To further investigate the mechanism of these microstructural changes, all samples were observed by SEM. Figure 13 shows the SEM images. Evidently, samples in their native state had intact crystal faces, crystals in close contact, and regular pores. Compared with the samples in their native state, some pores were closed in samples B-S-2 and C-S-1 under stress-induced damage, and their pore diameters were smaller. However, the microstructures for both samples B-S-2 and C-S-1 differed nonsignificantly from those of the samples in their native state. As a result of stress-induced damage, fine and long microcracks appeared on the internal crystal faces in sample D-S-3, and there were no accompanying cracks around the microcracks. In this sample, the crystal faces remained intact, but the pores were conspicuously closed. Due to the stressinduced damage, cracks began to develop on the crystal faces in sample E-S-3, and accompanying "wing-shaped" cracks appeared around the main cracks. In addition, intergranular cracks began to develop, and the cracks became wide. However, in this sample, the crystal faces remained intact. Moreover, notable pore closure occurred, and free detritus emerged near the pores in sample E-S-3. Because of the stress-induced damage, significant microstructural deterioration occurred for sample F-S-2. Its crystal faces

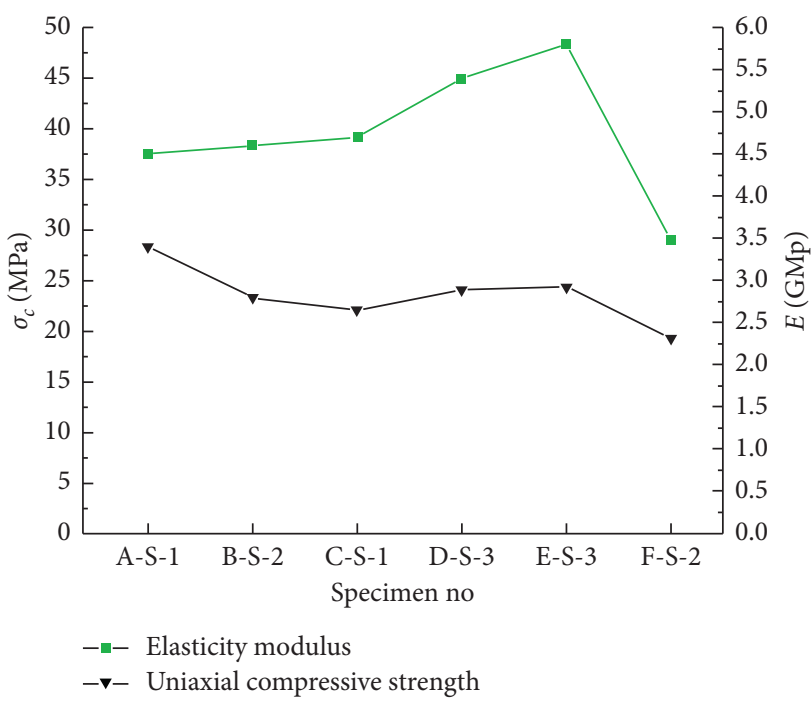

Figure 14: Line graphs of $\sigma_{c}$ and $E$.

showed breakage, shedding, and dislocation, and its pores fractured.

The uniaxial compression test results showed that stressinduced damage reduced the $\sigma_{c}$ values of rock samples. However, as $\sigma_{i}$ increased from 11.2 to $19.6 \mathrm{MPa}$, the $E$ values of the rock samples increased, as is shown in Figure 14. The 
TABLE 1: Correlation analysis of the microstructural and mechanical parameters under uniaxial compression.

\begin{tabular}{|c|c|c|c|c|c|c|c|c|c|}
\hline \multicolumn{2}{|c|}{ Parameters } & \multirow{3}{*}{$\begin{array}{c}N \\
1\end{array}$} & \multirow{3}{*}{$\begin{array}{c}\varphi \\
-0.275 \\
0.598 \\
\end{array}$} & \multirow{3}{*}{$\begin{array}{c}P_{\mathrm{I}} \\
0.528 \\
0.281\end{array}$} & \multirow{3}{*}{$\begin{array}{c}P_{\mathrm{II}} \\
0.167 \\
0.751\end{array}$} & \multirow{3}{*}{$\begin{array}{c}P_{\mathrm{III}} \\
-0.278 \\
0.594\end{array}$} & \multirow{3}{*}{$\begin{array}{c}P_{\mathrm{IV}} \\
-0.559 \\
0.249 \\
\end{array}$} & \multirow{3}{*}{$\begin{array}{c}\sigma_{c} \\
0.918 \\
0.010 \\
\end{array}$} & \multirow{3}{*}{$\begin{array}{c}E \\
0.598 \\
0.210 \\
\end{array}$} \\
\hline$N$ & $r$ & & & & & & & & \\
\hline$N$ & $P$ value & & & & & & & & \\
\hline \multirow{2}{*}{$\Phi$} & $r$ & -0.275 & 1 & -0.896 & -0.723 & 0.907 & 0.698 & -0.168 & -0.797 \\
\hline & $P$ value & 0.598 & & 0.016 & 0.104 & 0.013 & 0.123 & 0.751 & 0.058 \\
\hline \multirow{2}{*}{$P_{\mathrm{I}}$} & $r$ & 0.528 & -0.896 & 1 & 0.784 & -0.924 & -0.896 & 0.363 & 0.963 \\
\hline & $P$ value & 0.281 & 0.016 & & 0.065 & 0.008 & 0.016 & 0.479 & 0.002 \\
\hline \multirow{2}{*}{$P_{\mathrm{II}}$} & $r$ & 0.167 & -0.723 & 0.784 & 1 & -0.901 & -0.810 & -0.011 & 0.830 \\
\hline & $P$ value & 0.751 & 0.104 & 0.065 & & 0.014 & 0.051 & 0.983 & 0.041 \\
\hline \multirow{2}{*}{$P_{\mathrm{III}}$} & $r$ & -0.278 & 0.907 & -0.924 & -0.901 & 1 & 0.773 & -0.184 & -0.921 \\
\hline & $P$ value & 0.594 & 0.013 & 0.008 & 0.014 & & 0.071 & 0.727 & 0.009 \\
\hline \multirow{2}{*}{$P_{\mathrm{IV}}$} & $r$ & -0.559 & 0.698 & -0.896 & -0.810 & 0.773 & 1 & -0.267 & -0.889 \\
\hline & $P$ value & 0.249 & 0.123 & 0.016 & 0.051 & 0.071 & & 0.609 & 0.018 \\
\hline \multirow[b]{2}{*}{$\sigma_{c}$} & $r$ & 0.918 & -0.168 & 0.363 & -0.011 & -0.184 & -0.267 & 1 & - \\
\hline & $P$ value & 0.010 & 0.751 & 0.479 & 0.983 & 0.727 & 0.609 & & - \\
\hline \multirow{2}{*}{$E$} & $r$ & 0.244 & 0.585 & -0.525 & -0.910 & 0.767 & 0.523 & 0.357 & 1 \\
\hline & $P$ value & 0.641 & 0.223 & 0.285 & 0.012 & 0.075 & 0.287 & 0.488 & \\
\hline
\end{tabular}

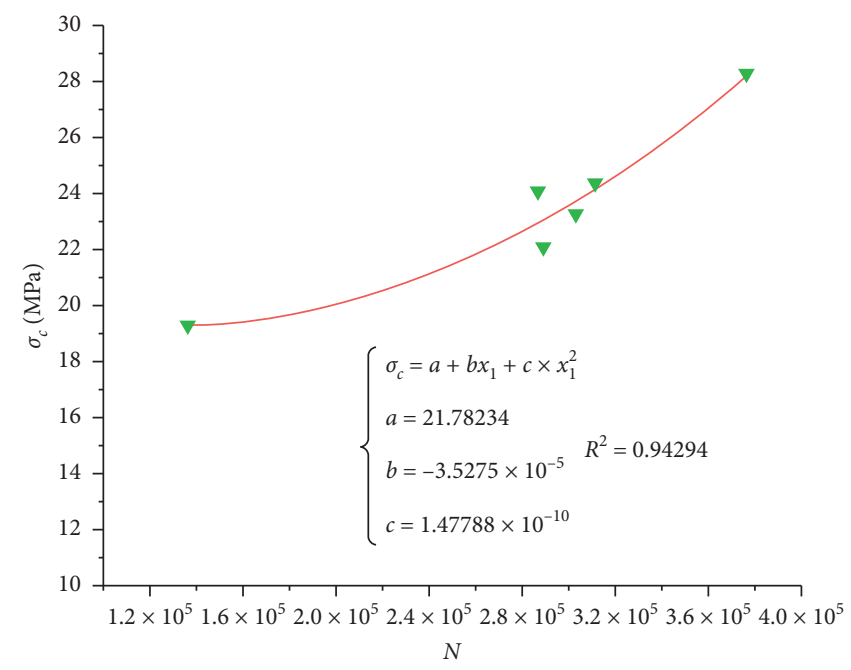

- Fitted curve

(a)

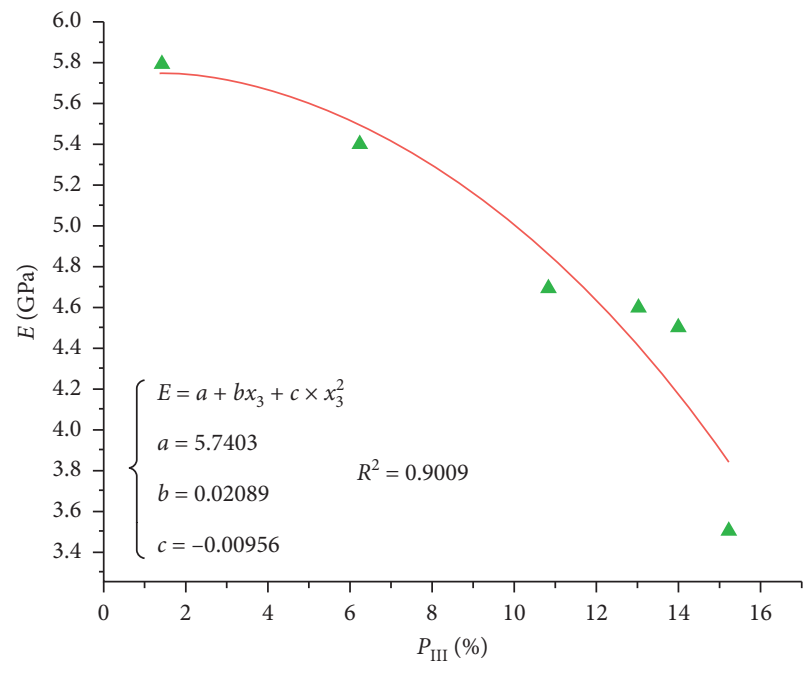

_ Fitted curve

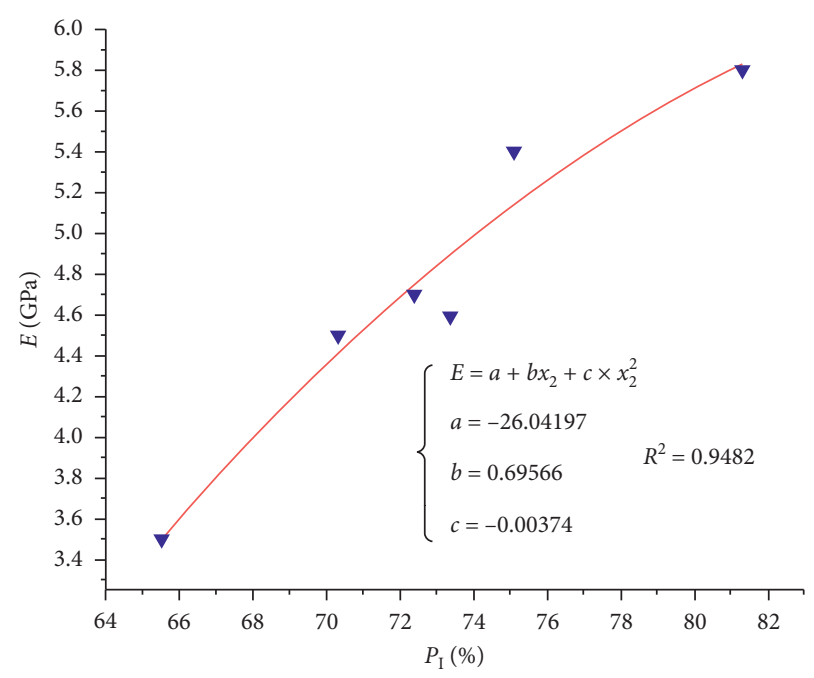

_ Fitted curve

(b)

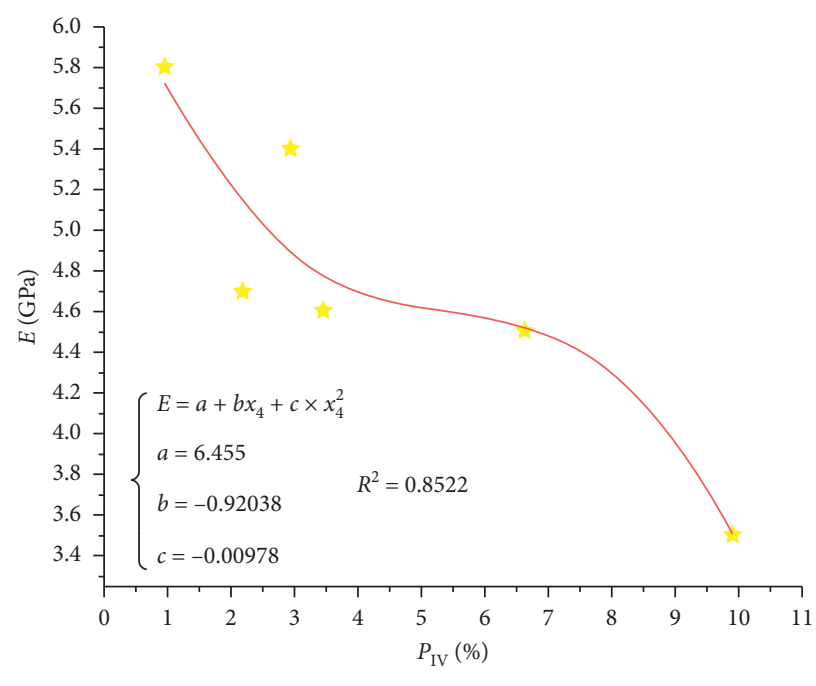

_ Fitted curve

(c)

(d)

FIGURE 15: Fitted curves of microstructural and macroscopic mechanical parameters. (a) Fitted curve of $N$ and $\sigma_{c}$. (b) Fitted curve of $E$ and $P_{\mathrm{I}}$ (c) Fitted curve of $E$ and $P_{\mathrm{III}}$. (d) Fitted curve of $E$ and $P_{\mathrm{IV}}$. 
correlations of the microstructures with $\sigma_{c}$ and $E$ were analyzed by a significance test [24]. Microstructural and mechanical parameters were subjected to significance tests using SPSS software. Table 1 summarizes the results. The $\sigma_{c}$ values of the soft rock were positively correlated with $N$. The $E$ values of the soft rock were uncorrelated with $N$ and $\varphi$. The $E$ values of the soft rock were positively correlated with $P_{\mathrm{I}}$ but were negatively correlated with $P_{\mathrm{III}}$ and $P_{\mathrm{IV}}$. The microstructural and mechanical parameters were fitted. Figure 15 shows the results.

\section{Conclusions}

In this study, samples of a soft rock which were damaged to various degrees under different stresses were subjected to SEM analysis, CT scanning, 3D reconstruction, and uniaxial compression testing. In addition, the sandstone pores were classified and characterized. The 3D reconstruction results visually displayed the effects of stressinduced damage on the internal microstructure of the soft rock. Finally, the correlations between the microstructural and mechanical parameters of the rock samples were analyzed.

The following conclusions were derived from this study: Stress-induced damage significantly affected the spatial distributions of internal pores of the rock. As $\sigma_{i}$ increased to $19.6 \mathrm{MPa}$, no cracks appeared in the rock, small pores were uniformly distributed but became increasingly interlinked, and large pores became decreasingly interlinked. As $\sigma_{i}$ increased beyond $19.6 \mathrm{MPa}$, noticeable microcracks appeared in the rock, and large pores were concentrated around cracks. Thus, from a microscopic perspective, crack formation was caused by spatial adjustment of the pore structure of the rock. As $\sigma_{i}$ increased, the $\sigma_{c}$ value of the rock decreased, albeit nonlinearly. As $\sigma_{i}$ increased, the $E$ value of the rock first increased and then decreased. As $\sigma_{i}$ increased to $19.6 \mathrm{MPa}, E$ increased. As $\sigma_{i}$ increased beyond 19.6 MPa, $E$ decreased considerably. The microstructural parameters of the stress-damaged soft rock were correlated with the mechanical parameters to a certain extent. In the stress-damaged soft rock, $\sigma_{c}$ and $N$ were strongly positively correlated. $E$ of the soft rock was positively correlated with $P_{\mathrm{I}}$ but negatively correlated with $P_{\mathrm{III}}$ and $P_{\mathrm{IV}}$. The results of this study can serve as a reference for evaluating rock damage and determining the microstructural mechanism of damage evolution in rocks. Moreover, the experimental design and approach used in this study can provide a basis for studying microstructural changes in and mechanical behaviors of rocks after sustaining damage. Furthermore, this study is valuable for safety evaluations and early-warning provisions for geotechnical engineering projects.

\section{Data Availability}

The datasets used or analyzed during the current study are available from the corresponding author upon reasonable request.

\section{Conflicts of Interest}

The authors declare no conflicts of interest.

\section{Acknowledgments}

This work was supported in part by the National Natural Science Foundation of China (51674149) and Shandong Provincial Natural Science Foundation, China (ZR2019MEE082).

\section{References}

[1] J. B. Zhu, T. Zhou, Z. Y. Liao, L. Sun, X. B. Li, and R. Chen, "Replication of internal defects and investigation of mechanical and fracture behaviour of rock using $3 \mathrm{D}$ printing and $3 \mathrm{D}$ numerical methods in combination with X-ray computerized tomography," International Journal of Rock Mechanics and Mining Sciences, vol. 106, pp. 198-212, 2018.

[2] W. Wang, S. Zhang, H. Li, S. Gong, and Z. Liu, "Analysis of the dynamic impact mechanical characteristics of prestressed saturated fractured coal and rock," Advances in Civil Engineering, vol. 2019, Article ID 5125923, 10 pages, 2019.

[3] Y. Chen and H. Lin, "Consistency analysis of Hoek-Brown and equivalent Mohr-Coulomb parameters in calculating slope safety factor," Bulletin of Engineering Geology and the Environment, vol. 78, no. 6, pp. 4349-4361, 2019.

[4] D. A. Lockner, J. D. Byerlee, V. Kuksenko, A. Ponomarev, and A. Sidorin, "Quasi-static fault growth and shear fracture energy in granite," Nature, vol. 350, no. 6313, pp. 39-42, 1991.

[5] E. Townend, B. D. Thompson, P. M. Benson, P. G. Meredith, P. Baud, and R. P. Young, "Imaging compaction band propagation in Diemelstadt sandstone using acoustic emission locations," Geophysical Research Letters, vol. 35, no. 15, Article ID L15301, 2008.

[6] S.-Q. Yang, P. G. Ranjith, Y.-H. Huang et al., "Experimental investigation on mechanical damage characteristics of sandstone under triaxial cyclic loading," Geophysical Journal International, vol. 201, no. 2, pp. 662-682, 2015.

[7] H. Kawakata, A. Cho, T. Kiyama, T. Yanagidani, K. Kusunose, and M. Shimada, "Three-dimensional observations of faulting process in westerly granite under uniaxial and triaxial conditions by X-ray CT scan," Tectonophysics, vol. 313, no. 3, pp. 293-305, 1999.

[8] Y. Chen, Y. Yang, F. Gao, and X. Zhang, "Researches on damage evolution and acoustic emission characteristics of rocks," Advances in Civil Engineering, vol. 2018, no. 4, Article ID 3108065, 7 pages, 2018.

[9] H. Q. Shuang, S. G. Li, L. Liu, G. F. Chen, and K. I. Song, "Use of acoustic emission for the detection of brittle rock failure under various loading rates," Advances in Civil Engineering, vol. 2018, Article ID 5735139, 9 pages, 2018.

[10] Z. Qin, H. Fu, and X. Chen, "A study on altered granite mesodamage mechanisms due to water invasion-water loss cycles," Environmental Earth Sciences, vol. 78, no. 14, p. 428, 2019.

[11] X. Yang, J. Wang, C. Zhu, M. He, and Y. Gao, "Effect of wetting and drying cycles on microstructure of rock based on SEM," Environmental Earth Sciences, vol. 78, no. 6, p. 183, 2019.

[12] M. Tao, H. Zhao, A. Momeni, Y. Wang, and W. Cao, "Fracture failure analysis of elliptical hole bored granodiorite rocks under impact loads," Theoretical and Applied Fracture Mechanics, vol. 107, Article ID 102516, 2020. 
[13] R. A. Ketcham and W. D. Carlson, "Acquisition, optimization and interpretation of X-ray computed tomographic imagery: applications to the geosciences," Computers \& Geosciences, vol. 27, no. 4, pp. 381-400, 2001.

[14] L. B. Wang, J. D. Frost, G. Z. Voyiadjis, and T. P. Harman, "Quantification of damage parameters using X-ray tomography images," Mechanics of Materials, vol. 35, no. 8, pp. 777-790, 2003.

[15] Y. Wang, D. Zhang, and Y. Z. Hu, "X-ray computed tomography characterization of soil and rock mixture under cyclic triaxial testing: the effects of confining pressure on meso-structural changes," Environmental Earth Sciences, vol. 78 , no. 6 , p. 185, 2019.

[16] H. Liu, G. Yang, Y. Yun et al., "Investigation of sandstone mesostructure damage caused by freeze-thaw cycles via CT image enhancement technology," Advances in Civil Engineering, vol. 2020, Article ID 8875814, 13 pages, 2020.

[17] Y. Wang, C. Li, J. Han, and H. Wang, "Mechanical behaviours of granite containing two flaws under uniaxial increasingamplitude fatigue loading conditions: an insight into fracture evolution analyses," Fatigue \& Fracture of Engineering Materials \& Structures, vol. 43, no. 9, pp. 2055-2070, 2020.

[18] S. Li, R. Huo, B. Wang et al., "Experimental study on physicomechanical properties of sandstone under acidic environment," Advances in Civil Engineering, vol. 2018, no. 4, Article ID 5784831, 15 pages, 2018.

[19] Z. T. Bieniawski and M. J. Bernede, "Suggested methods for determining the uniaxial compressive strength and deformability of rock materials. 1. Suggested method for determination of the uniaxial compressive strength of rock materials," International Journal of Rock Mechanics and Mining Sciences \& Geomechanics Abstracts, vol. 16, no. 2, pp. 137-138, 1979.

[20] Z. T. Bieniawski and M. J. Bernede, "Suggested methods for determining the uniaxial compressive strength and deformability of rock materials. 2. Suggested method for determining deformability of rock materials in uniaxial compression," International Journal of Rock Mechanics and Mining Sciences \& Geomechanics Abstracts, vol. 16, no. 2, pp. 138-140, 1979.

[21] Y. Lang, Z. Liang, D. Duan, and Z. Cao, "Three-dimensional parallel numerical simulation of porous rocks based on CT technology and digital image processing," Rock and Soil Mechanics, vol. 40, no. 3, pp. 1204-1212, 2019.

[22] B. Yu, "Classification and characterization of gas shale pore system," Earth Science Frontiers, vol. 20, no. 4, pp. 211-220, 2013.

[23] G. R. Chalmers, R. M. Bustin, and I. M. Power, "Characterization of gas shale pore systems by porosimetry, pycnometry, surface area, and field emission scanning electron microscopy/transmission electron microscopy image analyses: examples from the Barnett, Woodford, Haynesville, Marcellus, and Doig units," AAPG Bulletin, vol. 96, no. 6, pp. 1099-1119, 2012.

[24] Z. Wu and N. E. Huang, "Statistical significance test of intrinsic mode functions," in Hilbert-Huang Transform and Its Applications, N. E. Huang and S. S. P. Shen, Eds., pp. 107-127, World Scientific, Singapore, 2005. 